\title{
BMJ Open The impact of neurological disorders on the risk for falls in the community dwelling elderly: a case-controlled study
}

\author{
Barbara Homann, ${ }^{1}$ Annemarie Plaschg, ${ }^{1}$ Marion Grundner, ${ }^{1}$ Alice Haubenhofer, ${ }^{1}$ \\ Theresa Griedl, ${ }^{1}$ Gerd Ivanic, ${ }^{2}$ Edith Hofer, ${ }^{1}$ Franz Fazekas, ${ }^{1}$ \\ Carl Nikolaus Homann ${ }^{1,3}$
}

To cite: Homann B, Plaschg A, Grundner M, et al. The impact of neurological disorders on the risk for falls in the community dwelling elderly: a case-controlled study. BMJ Open 2013;3: e003367. doi:10.1136/ bmjopen-2013-003367

- Prepublication history for this paper is available online. To view these files please visit the journal online (http://dx.doi.org/10.1136/ bmjopen-2013-003367).

Received 7 June 2013 Revised 23 October 2013 Accepted 24 October 2013

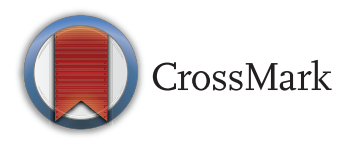

${ }^{1}$ Department of Neurology, Medical University Graz, Graz, Austria

${ }^{2}$ Department of Orthopaedic Surgery, Paracelsus Medical University Salzburg,

Salzburg, Austria

${ }^{3}$ Department of Public Health, St. Elisabeth University of Health and Social Sciences, Bratislava, Slowakia

Correspondence to Professor Carl Nikolaus Homann;

nik.homann@medunigraz.at, nick_homann@yahoo.de

\section{ABSTRACT}

Objectives: Owing to a lack of data, our aim was to evaluate and compare the impact of various common neurological diseases on the risk for falls in independent community dwelling senior citizens.

Design: Prospective case-controlled study.

Setting: General hospital.

Participants: Of 298 consecutive patients and 214 controls enrolled, 228 patients (aged 74.5 $\pm 7.8 ; 61 \%$ women) and 193 controls (aged $71.4 \pm 6.8 ; 63 \%$ women) were included. The exclusion criteria were as follows: for patients, severe disability, disabling general condition or severe cognitive impairment; for controls, any history of neurological disorders or disabling medical conditions; and for both, age below 60 years. A matching process led to 171 age-matched and gender-matched pairs of neurological patients and healthy controls.

Main outcome measures: A 1-year incidence of falls based on patients' 12-month recall; motor and non-motor function tests to detect additional risk factors.

Results: $46 \%$ of patients and $16 \%$ of controls fell at least once a year. Patients with stroke $(89 \%)$, Parkinson's disease $(77 \%)$, dementia $(60 \%)$ or epilepsy $(57 \%)$ had a particularly high proportion of fallers, but even subgroups of patients with the least fall-associated neurological diseases like tinnitus $(30 \%)$ and headache $(28 \%)$ had a higher proportion of fallers than the control group. Neuropathies, peripheral nerve lesions and Parkinson's disease were predisposing to recurrent falls. A higher number of neurological comorbidities $(p<0.001)$, lower Barthel Index values $(p<0.001)$, lower Activities-Specific Balance Confidence scores $(p<0.001)$ and higher Center of Epidemiological Studies Depression scores $(p<0.001)$ as well as higher age $(p<0.001)$ and female gender $(p=0.003)$ proved to further increase the risk of falls.

Conclusions: Medical practitioners, allied health professionals and carers should be aware that all elderly neurological patients seen in outpatient settings are potentially at high risk for falls; they should query them routinely about previous falls and fall risks and advise them on preventive strategies.

\section{Strengths and limitations of this study}

- The strengths of this study include the prospective study design, the number of standardised outcome measures, the standardised assessment of neurological patients and the thorough examination and inclusion of healthy controls.

- The following limitations should be considered: although the design is prospective, the falls history is retrospective, based on patients' recall over 12 months, and therefore under-reporting of cases is possible. There were small sample sizes in some of the subgroups of neurological diseases. Participants were mostly of Caucasian origin and there was a high dropout rate, which may limit the generalisability of the results to other populations.

\section{INTRODUCTION}

Owing to budget cuts and austerity measures, the costs of accidents and falls have come into the spotlight of health policymakers. The World Health Organisation too has recently made fall prevention in the elderly one of its top priorities. The WHO Global Report on Falls Prevention in Older Age states that due to the high percentage of elderly people worldwide, the economic and societal burden of falls will increase by epidemic proportions in all parts of the world over the next few decades, unless concerted action is taken in a systematic and proactive fashion by policymakers, researchers and practitioners.

It is known that falls in the elderly are common and have a great impact on life and well-being. Studies have shown that around $30 \%$ of participants aged 65 years plus had a fall during the last 12 months $^{2}$ with $10 \%$ sustaining severe injuries. ${ }^{3}$ Injuries are the fifth most frequent cause of death in the elderly and up to $70 \%$ of these injuries were caused by falls. ${ }^{4}$ Elderly persons surviving a fall 
experience significant morbidity: as many as one-third require assistance in their activities of daily living for as long as 6 months. ${ }^{5}$ Lasting disabilities are also common as many do not reach pre-fall physical functional states, resulting in increased dependency and (in up to 50\%) a transfer to a care facility. ${ }^{4}$ Associated as they are with considerable mortality as well as psychological and physical morbidity, these falls lead to increased dependence on social support and healthcare services, with high economic impact on the social and healthcare system. ${ }^{6}$ However, there is substantial evidence that falls can be prevented when participants at risk are identified and enrolled in targeted prevention programmes.

Several risk factors like sociodemographic variables, physical activity, alcohol consumption, acute and chronic health problems, dizziness, mobility and medications have been documented repeatedly. ${ }^{7}$ Neurological impairments in the elderly are also thought to increase the risk for falls, though evidence for this is mostly derived indirectly from investigations into the causes of falls in the elderly. ${ }^{8}$ These studies show that patients admitted to hospitals due to falls frequently also suffer from neurological disorders. Data derived from a multidisciplinary fall consultation survey suggest that in two of three patients, potentially fall-inducing neurological disorders were present, most of them $(85 \%)$ previously undiagnosed. ${ }^{9}$

However, there is substantially less knowledge about the risk for falls in patients afflicted with various common neurological diseases. While there is already a substantial amount known about the increased risk of falls in the stroke, ${ }^{10}$ Parkinson's disease (PD) ${ }^{11}$ or dementia ${ }^{12}$ population, to our knowledge there is only one comparative study investigating falls in patients with a broad range of neurological diseases. This study by Stolze et al, ${ }^{13}$ however, was conducted on patients with neurological diseases severe enough to require hospital admission. Until now, little is known about the risk of falling in independent, community dwelling senior citizens afflicted with neurological diseases treatable in outpatient facilities. Studies targeting this issue so far either did not use a control group or, if they did, the absence of neurological signs and symptoms in this cohort was not guaranteed.

However, because falls in community dwelling elderly patients are assumed to be prevalent as well as preventable, neurologists in outpatient settings need a sound base to identify patients with the highest risk to reduce not only the number of falls and the suffering they entail but also the overall healthcare costs. Our study thus aimed to investigate the risk of falls in elderly patients with various neurological diseases that are commonly encountered in outpatient facilities. We hypothesised that even in community dwelling elderly patients, the impact of one or more neurological diseases on top of an already increased propensity for falls is substantial; that patients with certain diseases like stroke or PD are particularly at risk; and that affliction with more than one of these high-risk diseases increases the risk even further.

\section{PARTICIPANTS AND METHODS}

\section{Setting}

Data were collected at the general outpatient department of the Department of Neurology of the University Hospital in Graz, Austria. As visits to the outpatient department do not require specialist referrals, the disease spectrum largely resembles that seen by community-based neurologists.

\section{Selection of participants and baseline examination}

Physically independent community dwelling patients aged 60 years and older who were treated in our general neurological outpatient clinic were included in the study. Patients were all seen consecutively by one and the same consultant $(\mathrm{CNH})$ in the period from July 2007 to May 2008, which also explains the study size. Severely disabled patients who were no longer able to walk unaided or were in poor general condition, be it for reasons of neurological or other medical disease, were excluded from the study. Cognitive impairment to an extent that an interview would no longer yield reliable results (MMSE $\leq 12)$ was also a cause for exclusion. All neurological patients included underwent a full neurological workup with an extensive history to detect signs of past and present neurological disorders. For the sake of uniformity, both the workup and history were structured and followed the study protocol.

As healthy controls, individuals from the general public out of the same catchment area as cases were enrolled. They were recruited among friends and acquaintances of the author and his co-workers who were aged $60+$ and without any history of neurological disorders or other disabling medical conditions like heart failure, chronic obstructive pulmonary disease or rheumatoid arthritis severe enough to cause limitation of ordinary physical activity. Examination and history were as per study protocol, whereby special emphasis was placed on identifying symptoms and signs of PD, peripheral neuropathy, stroke or epilepsy, as well as minor sensory-motor deficits and gait or balance impairments. Controls with even subtle neurological pathologies were excluded. Although not routinely screened for cognitive deficits, obvious signs of a known diagnosis of dementia or even of mild cognitive impairment were a reason for exclusion.

A telephonic follow-up was scheduled 12 months after the baseline outpatient visit; it was carried out by one of the two examiners (AP and MG) following a predefined format and only participants who had given verbal informed consent at the start of the telephone contact were interviewed.

The first section of the interview questionnaire covered demographic data like age and place of residence. The residence category had five subsections on size and traffic infrastructure, with group 1 being the state capital and group 5 a small town in the periphery. Next were specific questions on fall frequency, physical disability, depression and confidence in one's own sense 
of balance. The final section dealt with risk situations (like when using public transport) and general mobility issues, whereby the latter are not included in this publication.

\section{Frequency of falls}

In the main section of the questionnaire, patients and healthy controls were asked whether they had had a fall during the past 12 months and, if yes, how many times they had fallen. The yearly fall incidence was graded according to the fall frequency index into five categories. Category I means 1-2 falls, category II 3-5 falls, category III 6-10 falls, category IV 11-20 falls, and category $\mathrm{V}$ more than 20 falls.

\section{Disability}

The Barthel Index,${ }^{14}$ a disability scale with scores from 0 (completely dependent) to 100 (completely independent), was used to evaluate the functional status of all neurological patients.

Patients with PD were also rated according to the Schwab and England Scale and Part II of the Unified Parkinson's Disease Rating Scale (UPDRS).$^{15}$

\section{Depression}

To determine the grade of depression, the Allgemeine Depressionsskala Kurzform (ADS-K), ${ }^{16}$ the German short form for the Center of Epidemiological Studies Depression Scale (CES-D), ${ }^{17}$ was used. It is known to be particularly well suited for use in the elderly and in patients with certain neurological disabilities. ${ }^{18}$

\section{Balance confidence}

We also rated the patients' confidence in their own sense of balance with the Activities-Specific Balance Confidence Scale (ABC 6 scale). ${ }^{19}$ Participants judged their confidence in performing specific activities without loss of balance or being unsteady on a scale ranging from $0 \%$ (no confidence at all) to $100 \%$ (complete confidence). The total score was then computed as an average of the subscores.

\section{Statistical analysis}

The primary outcomes were falls, based on participant recall over the previous 12 months. Falls were defined according to the WHO definition ${ }^{1}$ as an event which results in a person coming to rest inadvertently on the ground or floor or other lower level irrespective of cause, thus including, for example, falls from epileptic seizures. The 1-year incidence of falls was calculated for healthy elderly individuals as well as the whole sample of neurological patients. Further calculations were performed for subsamples of 13 neurological disorders with the highest prevalence $(n \geq 7)$. The diagnoses were based on the International Classification of Diseases 10th revision (ICD-10) system for classification of diseases. The means and SDs were calculated for numerical values like the rating scale scores. For the identification of fall related risk factors, correlations (Kendall's $\tau-\mathrm{B}$ ) and, for the individual neurological disorders, ORs were computed $(\alpha$-level of significance $\mathrm{p}<0.05)$. Differences between neurological patients and healthy controls were tested with the Mann-Whitney $U$ test or the $\chi^{2}$ test $(\alpha$-levels of significance $\mathrm{p}<0.05$ ). To ensure comparability of cohorts, we formed age-matched and gender-matched pairs of patients and control participants. For the matching process, we used alphabetical lists of names of male and female neurological patients and, likewise, of healthy controls, sorted by age. Then, working down the list, we searched manually to find for each neurological patient one control participant of the same age. If no match was found, we looked for a control that was 1 year younger, then 1 year older, then 2 years and finally 3 years younger, respectively, older. Only complete sets of data were included in the calculations and no approximates to replace missing values were computed. Calculations were performed with SPSS statistical software PASW statistics V.18. Potential bias and how it was addressed will be dealt with in the section on limitations.

\section{RESULTS}

During a period of 10 months, we recruited 298 mobile neurological outpatients and 214 healthy controls aged 60 years and over. In the group of healthy controls, 21 patients initially recruited could not be included in the study due to neurological symptoms and signs, or a history of neurological disorder. In the group of neurological patients, another 70 patients had to be excluded from the study because, at the time of the interview, they $(\mathrm{n}=10)$ or their caregiver $(\mathrm{n}=6)$ requested exclusion, the telephone number on record had been disconnected $(n=24)$, all attempts to contact them failed $(n=11)$, they had become so disabled that they could no longer participate in the survey $(n=10)$, they had died $(n=4)$ or for other reasons $(\mathrm{n}=5)$.

Prior to recruitment, 20 patients were excluded because of an inability to walk unaided and 1 due to severe dementia. Of those who met the inclusion criteria, five rejected enrolment and six others could not be enrolled due to inadequate language skills $(n=1)$, severe aphasia $(n=1)$ or severe presbyacusis $(n=4)$.

The statistical analysis thus covered 228 neurological outpatients (aged 74.5 $\pm 7.8 ; 61 \%$ women) and 193 healthy controls. The matching process led to 171 pairs of neurological patients and healthy controls, 101 women and 70 men in each group, aged 72 and 72.2 years, respectively. The details of these participants are summarised in table 1.

\section{Incidence of falls in neurological patients and healthy controls}

One hundred and six (46.5\%) neurological patients but only $31(16.1 \%)$ healthy controls had fallen at least once $\left(\chi^{2}=43.4 ; \mathrm{p}<0.001\right)$ during this 1-year period. Out of 106 neurological patients experiencing falls, $76(71.7 \%)$ fell 
Table 1 Neurological patients and healthy controls: general demographics and fall frequency

\begin{tabular}{|c|c|c|c|c|c|c|}
\hline & \multicolumn{3}{|l|}{ Total } & \multicolumn{3}{|c|}{ Matched pairs } \\
\hline & $\begin{array}{l}\text { Patients } \\
(n=228)\end{array}$ & $\begin{array}{l}\text { Healthy } \\
(n=193)\end{array}$ & $\begin{array}{l}\mathbf{p} \\
\text { Value }\end{array}$ & $\begin{array}{l}\text { Patients } \\
(n=171)\end{array}$ & $\begin{array}{l}\text { Healthy } \\
(n=171)\end{array}$ & $\begin{array}{l}\mathbf{p} \\
\text { Value }\end{array}$ \\
\hline \multicolumn{7}{|l|}{ Total } \\
\hline Age & $74.5 \pm 7.8$ & $71.4 \pm 6.8$ & 0.000 & $72.2 \pm 7.0$ & $72.0 \pm 6.9$ & 0.839 \\
\hline Gender ( $f$ in \%) & $61 \%$ & $63 \%$ & 0.572 & $59 \%$ & $59 \%$ & 1.000 \\
\hline Region (residential index: mean) & 2.53 & 2.21 & 0.021 & 2.66 & 2.22 & 0.004 \\
\hline Disability (Barthel index: mean) & 98.20 & & & 98.24 & & \\
\hline Balance (ABC-score: mean) & 73.19 & & & 83.39 & & \\
\hline Depression (ADS-K-score: mean) & 7.2 & & & 6.9 & & \\
\hline \multicolumn{7}{|l|}{ Fallers } \\
\hline Falls (n (\%)) & $46.5 \%$ & $16.1 \%$ & 0.000 & $42.1 \%$ & $16.9 \%$ & 0.000 \\
\hline Multiple falls (>2 falls) (n (\%)) & $28.3 \%$ & $22.6 \%$ & 0.528 & $26.4 \%$ & $24.1 \%$ & 0.815 \\
\hline Fall frequency index (in fallers) & $1.42 \pm 0.8$ & $1.23 \pm 04$ & 0.078 & $1.44 \pm 0.9$ & $1.24 \pm 04$ & 0.14 \\
\hline
\end{tabular}

once or twice, $22(20.8 \%) \quad 3-5$ times, 3 (2.8\%) $6-9$ times, 3 (2.8\%) 11-20 times and $2(1.9 \%)$ more than 20 times. In the group of healthy controls, of 31 individuals with a history of falls, $24(77.4 \%)$ fell once or twice, and $7(22.6 \%)$ three to five times, but none more often than that. In the matched cohorts as well, falls were more frequent in neurological patients $(42.1 \%)$ than in healthy controls $(16.9 \%)\left(\chi^{2}=26.3 ; \mathrm{p}<0.001\right.$; table 1$)$.

The mean age of individuals with a history of falls as compared to those without was higher in the neurologically affected (fallers $76.7 \pm 7.6$ vs non-fallers $72.6 \pm 7.5$; $\mathrm{p}<0.001$ ) as well as in healthy controls (fallers $73.3 \pm 6.5$ vs non-fallers $71.0 \pm 6.9 ; \mathrm{p}=0.040)$. In the group of neurological patients, 75 of 106 fallers $(71 \%)$ were female, but only $31(29 \%)$ were male $\left(\chi^{2}=8.675 ; \mathrm{p}=0.003\right)$. Similarly, in the group of healthy controls, a higher percentage of fallers was female, with 23 of $31(74 \%)$, but this did not reach significance $\left(\chi^{2}=1.915 ; \mathrm{p}=0.166\right)$.

The occurrence of falls in neurological patients was independent of where they lived. For healthy controls, however, their place of residence had an influence, in that participants living in more rural environments were more prone to falls $(\Gamma-\mathrm{B}=0.217 ; \mathrm{p}<0.001)$.

Multiple falls occurred particularly in patients with peripheral neuropathy $(43 \%)$, peripheral nerve lesion $(43 \%)$, dementia $(33 \%)$, PD $(30 \%)$, stroke $(30 \%)$ and vertebral pain $(30 \%)$. The average fall frequency index in this group of five diseases ranged from 1.63 (peripheral neuropathy) to 1.33 (dementia). The proportion of fallers in each index category is shown for all these diseases in figure 1.

\section{Risk factors for falls in neurological patients}

The type of neurological disease the patient was afflicted with influenced the proportion of fallers in that patients poststroke $(89 \%)$, with PD $(77 \%)$, dementia $(60 \%)$ and epilepsy $(57 \%)$, had the highest frequency of falls. The lowest likelihood of falls was found in patients suffering from tinnitus $(30 \%)$ and headache $(28 \%)$, but it was still higher than that of the average healthy control $(16.1 \%$; figure 2).

The respective ORs are shown in table 2 and range from 40.1 (stroke) to 2.1 (headache) and the relative risk of falling ranges between 5.5 for patients with stroke and 1.8 for patients with headache.

No specific combination of two or three neurological diseases was characterised by substantial gait or balance impairment, but any accumulation of several neurological diseases regardless of their influence on gait or balance was able to cause a significant raise in falls $(\Gamma-\mathrm{B}=0.303 ; \mathrm{p}<0.001$ ) (figure 3$)$.

Other risk factors for falls in neurological patients were female gender $(\Gamma-B=0.195 ; p=0.003)$, higher age $(\Gamma-\mathrm{B}=0.217 ; \mathrm{p}<0.001)$, higher disability or disease severity as measured by the Barthel Index $(\Gamma-B=-0.232$; $\mathrm{p}<0.001)$. Higher disability scores in patients with PD expressed by higher UPDRS II (activities of daily living) scores $(\Gamma-B=-0.238 ; p=0.062)$ and higher Schwab and England scores $(\Gamma-\mathrm{B}=-0.235 ; \mathrm{p}=0.070)$ resulted in a trend towards more frequent falls. Severity of depression, as reflected by a higher $\mathrm{ADS}$ score $(\Gamma-\mathrm{B}=0.329$; $\mathrm{p}<0.001)$, and low balance confidence, as reflected by lower ABC scores $(\Gamma-\mathrm{B}=-0.384 ; \mathrm{p}<0.001)$, were also identified as risk factors (figure 3).

\section{DISCUSSION}

\section{Incidence of falling}

Our study suggests that even in patients mildly to moderately affected by neurological impairments, the incidence of falls was three times higher than in participants without any neurological symptoms or signs. To our knowledge, this is the first survey conducted on elderly neurological outpatients and controls proven to be without neurological impairments, but the extent of this increased relative risk in neurological patients was unexpected and resulted from low incidence figures in the group of controls and particularly high figures in the patient group. 


\section{Percentage of Fallers in various Neurological Diseases according to FFI Categories}

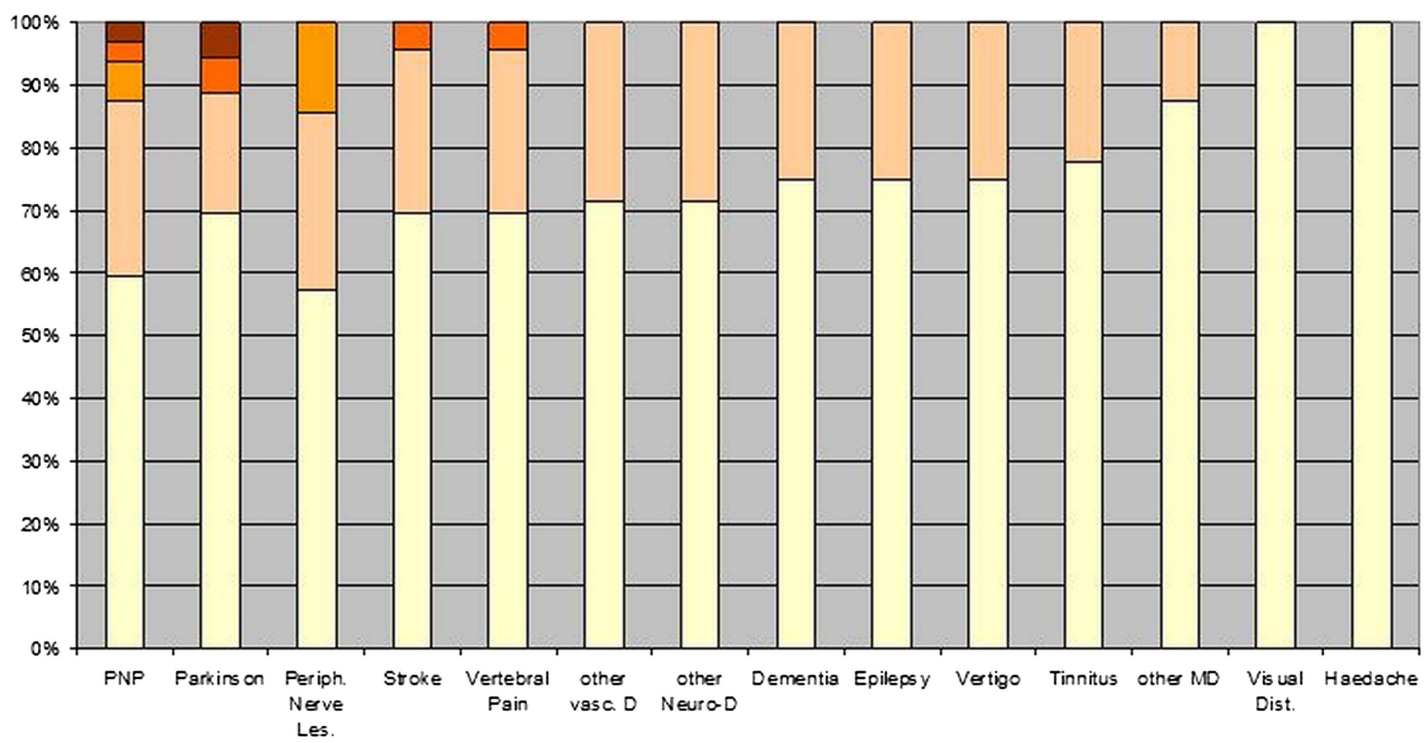

\begin{tabular}{|c|c|c|c|c|c|c|c|c|c|c|c|c|c|c|}
\hline $\begin{array}{l}\text { Cate- } \\
\text { gories }\end{array}$ & $\begin{array}{l}\text { PNP } \\
\text { (n) }\end{array}$ & $\begin{array}{l}\text { PD } \\
\text { (n) }\end{array}$ & $\begin{array}{l}\text { PNL } \\
\text { (n) }\end{array}$ & $\begin{array}{c}\text { Strok } \\
\text { e } \\
\text { (n) }\end{array}$ & $\begin{array}{c}\text { Vert } P \\
\text { (n) }\end{array}$ & $\begin{array}{l}\text { other } \\
\text { vasc } \\
\text { (n) }\end{array}$ & $\begin{array}{l}\text { Other } \\
\text { n. D. } \\
\text { (n) }\end{array}$ & $\begin{array}{l}\text { Dem } \\
\text { (n) }\end{array}$ & $\begin{array}{l}\text { Epi } \\
\text { (n) }\end{array}$ & $\begin{array}{c}\text { Vertig } \\
\text { (n) }\end{array}$ & $\begin{array}{c}\text { Tinni- } \\
\text { tus } \\
\text { (n) }\end{array}$ & $\begin{array}{c}\text { other } \\
\text { MD } \\
\text { (n) }\end{array}$ & $\begin{array}{c}\text { Visual } \\
\text { Dist } \\
\text { (n) }\end{array}$ & $\begin{array}{c}\text { Haed- } \\
\text { ache } \\
\text { (n) }\end{array}$ \\
\hline $\mathrm{V}$ & 1 & 2 & 0 & 0 & 0 & 0 & 0 & 0 & 0 & 0 & 0 & 0 & 0 & 0 \\
\hline III & 2 & 0 & 1 & 0 & 0 & 0 & 0 & 0 & 0 & 0 & 0 & 0 & 0 & 0 \\
\hline II & 9 & 7 & 2 & 6 & 6 & 4 & 4 & 1 & 1 & 3 & 2 & 1 & 0 & 0 \\
\hline 0 & 27 & 11 & 11 & 3 & 15 & 11 & 20 & 3 & 3 & 18 & 21 & 6 & 6 & 10 \\
\hline Total & 59 & 47 & 18 & 26 & 48 & 25 & 34 & 7 & 7 & 30 & 30 & 14 & 10 & 14 \\
\hline
\end{tabular}

Figure 1 Frequency of falls in neurological patients according to their neurological disorder. Fall frequency index (FFI) category $\mathrm{I}=1-2$ falls in the last 12 months, category $\mathrm{II}=3-5$, category $\mathrm{II}=6-10$, category $\mathrm{IV}=11-20$, and category $\mathrm{V}=$ more than 20.

In our group of healthy controls, the 12-month incidence $(16.1 \%)$ was considerably lower than in previous population-based data serving as a reference for previous studies. ${ }^{20}$ The literature suggests that a third to one-half of the community dwelling population of $60+$ experience falls each year. For a group of 1762 participants $60+$ years of age, Lord $e t a l^{21}$ reported a yearly incidence rate of falls of $28 \%$. In individuals of 65 years and older, Prudham found in his survey conducted on 2793 individuals that $28 \%$ experienced one or more falls in
Figure 2 Difference in frequency of having at least one fall within the 12-month period for patients suffering from the 13 most commonly encountered neurological disorders.
One year fall incidence in common neurological disorders

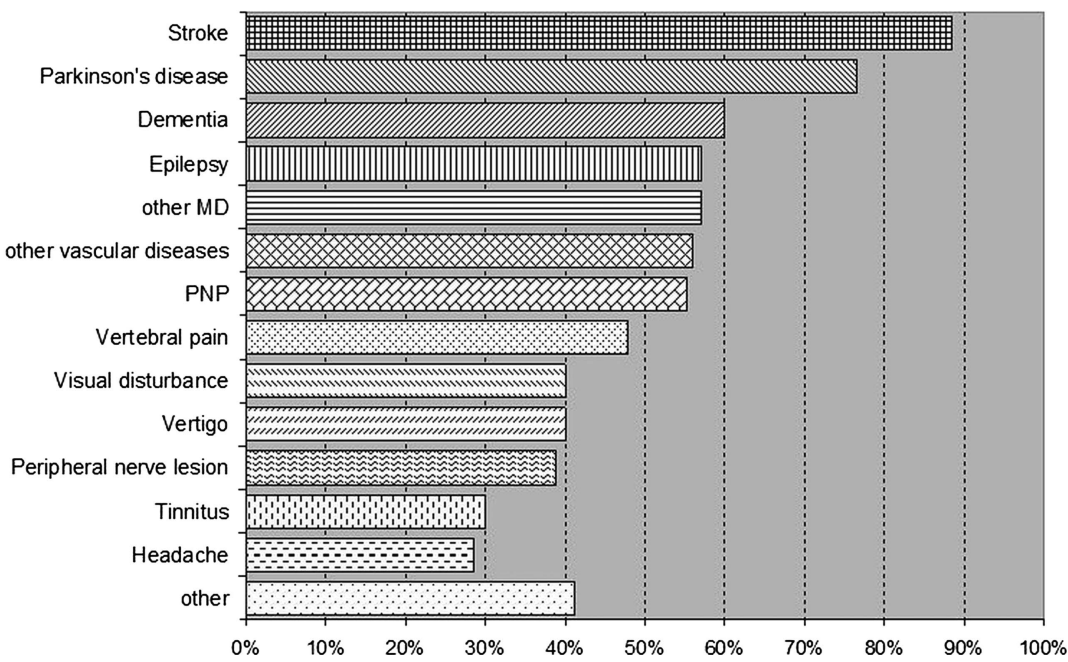


Table 2 Neurological patient groups: general demographics and fall risk

\begin{tabular}{|c|c|c|c|c|c|c|c|c|c|}
\hline \multirow[b]{2}{*}{ Diagnosis } & \multirow[b]{2}{*}{ Age } & \multirow[b]{2}{*}{ Barthel } & \multirow[b]{2}{*}{ Total (n) } & \multirow[b]{2}{*}{$\begin{array}{l}\text { Falls } \\
(n(\%))\end{array}$} & \multirow[b]{2}{*}{$\begin{array}{l}\text { Multiple } \\
\text { falls* (n (\%)) }\end{array}$} & \multirow[b]{2}{*}{$\begin{array}{l}\text { Fall frequency } \\
\text { (in fallers) }\end{array}$} & \multicolumn{3}{|c|}{ Risk of falling } \\
\hline & & & & & & & OR & $\mathrm{CI}$ & $\begin{array}{l}\mathbf{p} \\
\text { Value }\end{array}$ \\
\hline Stroke & $82.7 \pm 2.3$ & 99.76 & 26 & $23(89)$ & $7(30)$ & $1.39 \pm 0.72$ & 40.1 & (11.3 to 141.7 ) & 0.000 \\
\hline $\begin{array}{l}\text { Parkinson's } \\
\text { disease }\end{array}$ & $74.8 \pm 8.1$ & 99.79 & 47 & $36(77)$ & $11(31)$ & $1.58 \pm 1.13$ & 17.1 & (7.9 to 37.2 ) & 0.000 \\
\hline Dementia & $77.5 \pm 9.2$ & 99.77 & 7 & $3(60)$ & $1(33)$ & $1.33 \pm 0.58$ & 7.8 & (1.3 to 48.9 ) & 0.01 \\
\hline Epilepsy & $71.0 \pm 8.2$ & 99.78 & 7 & $4(57)$ & $1(25)$ & $1.25 \pm 0.5$ & 7.0 & (1.5 to 32.7 ) & 0.005 \\
\hline $\begin{array}{l}\text { Other medical } \\
\text { disease }\end{array}$ & $74.3 \pm 7.9$ & 100 & 14 & $8(57)$ & $1(13)$ & $1.23 \pm 0.82$ & 7.0 & (2.3 to 21.5 ) & 0.000 \\
\hline $\begin{array}{l}\text { Other vascular } \\
\text { disease }\end{array}$ & $74.8 \pm 8.1$ & 99.79 & 25 & $14(56)$ & $4(29)$ & $1.29 \pm 0.47$ & 6.7 & (2.8 to 16.0$)$ & 0.000 \\
\hline PNP & $71.0 \pm 8.1$ & 99.78 & 58 & $32(55)$ & $13(43)$ & $1.63 \pm 0.98$ & 6.4 & (3.4 to 12.3 ) & 0.000 \\
\hline Vertebral pain & $76.8 \pm 9.1$ & 99.75 & 48 & $23(48)$ & $7(30)$ & $1.39 \pm 0.72$ & 4.8 & (2.4 to 9.5 ) & 0.000 \\
\hline $\begin{array}{l}\text { Visual } \\
\text { disturbance }\end{array}$ & $69.5 \pm 0.7$ & 99.77 & 10 & $4(40)$ & $0(0)$ & $1 \pm 0$ & 3.5 & (0.9 to 13.1$)$ & 0.051 \\
\hline Vertigo & $72.0 \pm 8.1$ & 99.75 & 30 & $12(40)$ & $3(25)$ & $1.25 \pm 0.45$ & 3.5 & (1.5 to 8.0 ) & 0.002 \\
\hline $\begin{array}{l}\text { Peripheral } \\
\text { nerve lesions }\end{array}$ & $66.0 \pm 8.1$ & 99.79 & 18 & 7 (39) & $3(43)$ & $1.57 \pm 0.79$ & 3.3 & (1.2 to 9.2 ) & 0.016 \\
\hline Tinnitus & $74.3 \pm 8.4$ & 99.76 & 30 & $9(30)$ & 2 (22) & $1.22 \pm 0.44$ & 2.2 & (0.9 to 5.3 ) & 0.064 \\
\hline Headache & $74.8 \pm 8.1$ & 99.79 & 14 & $4(29)$ & $0(0)$ & $1.0 \pm 0.0$ & 2.1 & (0.6 to 7.1$)$ & 0.228 \\
\hline Other & $79.4 \pm 7.1$ & 99.74 & 34 & $14(41)$ & $4(29)$ & $1.29 \pm 0.47$ & 3.7 & (1.7 to 8.0 ) & 0.001 \\
\hline
\end{tabular}

*Multiple falls were defined as more than two falls per year (ie, a fall frequency index $\geq 2$ ).

†Fall frequency index: category $\mathrm{I}=1-2$ falls in the last 12 months, category $\mathrm{II}=3-5$ falls in the last 12 months, category $\mathrm{III}=6-10$ falls in the last 12 months, category IV=11-20 falls in the last 12 months, and category V=more than 20 falls in the last 12 months.

the previous year. ${ }^{22}$ In O'Loughlin et $a l^{7}{ }^{7}$ group of 409 , it was $29 \%$, in Campbell et al $\mathrm{s}^{23}$ group of $533,33 \%$ and in Blake et $a l \mathrm{~s}^{24}$ group of $1042,35 \%$. Luukinen et $a l \mathrm{~s}^{3}$ group of 833 individuals aged $70+$ showed a $30 \%$ annual rate of falls and Tinetti et $a l \mathrm{~s}^{25}$ group of 336 aged $75+$ showed a rate of $32 \%$. For the very old, Campbell found in a community-based prospective study based on 761 participants that half of those aged 80 years and over have a fall every year. ${ }^{26}$ This incidence rate, two or three times that of our figures, did not surprise us. Population-based data of elderly individuals inevitably include a considerable number of patients suffering from neurological diseases or other forms of gait or balance problems. Many of these neurological disorders like stroke, Alzheimer's disease or PD are typical diseases of the elderly, and others like epilepsy or traumatic brain injury also have a second peak in higher age. ${ }^{27}$ This shows that it can be of advantage, when studying groups of elderly patients, to have a truly healthy control group, as in our survey.

Our study also shows that half of all ambulatory neurological patients had had at least one fall within the past 12 months. As to our knowledge this is the first survey of neurological outpatients, the lack of comparative data gave us no choice but to relate our findings to Stolze et $a l \mathrm{~s}^{13}$ data on neurological inpatients showing, much to our surprise, a falling incidence as low as $34 \%$. One would have assumed that Stolze's patients, who required inpatient treatment for their neurological conditions, would be more severely disabled and thus more prone to falls than outpatients. It also appears contradictory to our findings that indicators of disease severity like the
Figure 3 Differences in ABC 6 scores $(A)$ and number of NDs (B) of neurological patients with and without falls indicate that fallers as compared to non-fallers have lower confidence in their balance and a higher number of concomitant NDs. (ABC 6\%, percentage scores of the 6-item version of the Activities-Specific Balance Confidence scale, number of ND, number of neurological diseases a patient is afflicted with). (a) Balance confidence and occurrence of falls

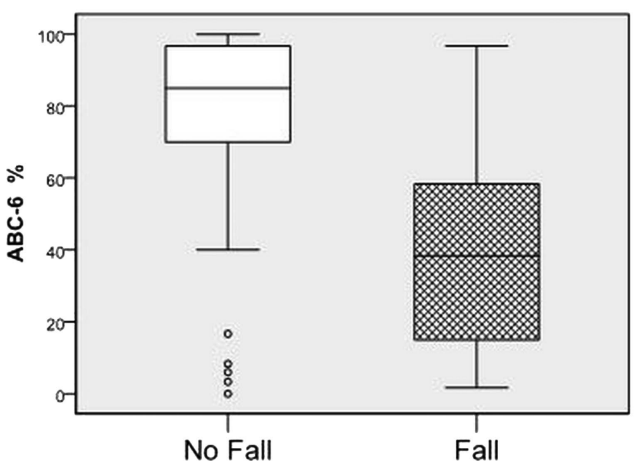

(b) Neurological comorbidities and falls

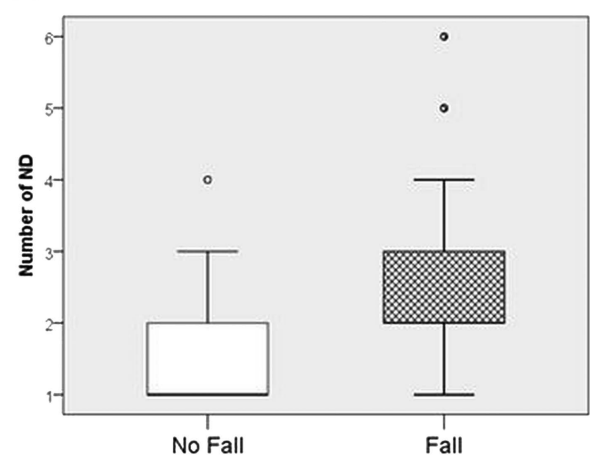


Barthel index and the UPDRS II correlated positively with the incidence of falls. Several studies further support this concept by stating that the more severely affected patients are, the higher the falling risk. ${ }^{28}$ However, we have reasons to believe that the correlation is not linear throughout all grades of disability but rather resembles an inverse U-shaped curve. We think that the initial propensity for falls increases with higher disability only up to a certain point. Then, as patients become more cautious and use all kind of supports, it plateaus and even decreases. When patients become so disabled that they are finally bedridden, the risk approaches zero with the lack of opportunities to fall. Therefore, our values would be located on the inclining leg close to the peak and Stolze's further down on the declining leg. Since this concept has as yet only been proposed for $\mathrm{PD}^{29}$ but not for other neurological conditions, further studies directly comparing the risk of falling in neurological inpatients and outpatients of various grades of disability are needed to support this assumption.

Considering recurrent falls, we found that in the group of neurological patients $13.2 \%$ fell three or more times per year, compared to $3.6 \%$ in the group of healthy controls. This is in keeping with the results of studies investigating recurrent falls, where figures are given of $8 \%$ for three or more falls in randomly selected community dwelling elderly individuals ${ }^{30}$ and $10 \%$ for community-based seniors using home care services. ${ }^{31}$ In Stolze's cohort of inpatients, the value of $21 \%$ for recurrent falls was higher and can probably be explained by methodological differences. Stolze's category of recurrent falls already includes patients who had fallen twice, unlike our and other studies ${ }^{30} 31$ that include patients only after more than three falls.

\section{Risk factors contributing to falls}

We found that the type of neurological disease afflicting a patient determines the potential risk factor for falls. Here, two diseases stood out: patients with stroke were six times $(89 \%)$ and patients with PD five times $(71 \%)$ more likely to suffer falls than healthy controls $(16 \%)$. This is in keeping with previous community-based studies showing a high likelihood for falls in patients with stroke with a range of $51-73 \%^{10} \quad 20 \quad 32$ and in patients with Parkinson's disease with a range of 38$87 \% .^{33-39}$ This was followed by a group of neurological diseases with an almost four times higher likelihood (55-60\%) of falls, consisting of dementia, epilepsy, other movement disorders, other vascular diseases and peripheral neuropathy. These diseases are also known to carry a high risk for falls, with an annual fall rate of 60$80 \%^{12} 40$ in patients with Alzheimer's disease and 55$65 \%^{41-43}$ in patients with peripheral neuropathy. The only study conducted on falls in elderly patients suffering from epilepsy is one on care facility residents, providing a 5-year fall incidence of $83 \% .^{44}$ In our sample, peripheral neuropathy also proved to be a risk factor for recurrent falls, but significance was not reached most likely due to the small sample size $(\mathrm{p}=0.061)$. Also, confirmative data obtained from small cohorts revealed that multiple falls occurred in 10 of $25(40 \%)$ patients with neuropathy ${ }^{43}$ and another 13 of 20 patients with neuropathy $(65 \%)$ had a propensity for multiple falls for an average of 5.8 falls/year. ${ }^{41}$ New and unexpected was the fact that even patients suffering from neurological diseases with no direct influence on gait or balance like headache $(28 \%)$ had almost twice as many falls as the average healthy control $(16.1 \%)$. Also new is that, in contrast to all the above cited data derived from studies on patients with only one neurological disorder, our survey provides comparative values for several neurological diseases of elderly ambulatory neurological patients for the first time, allowing a direct comparison between these disorders and a ranking according to the risk of falling.

However, our findings further suggest that not only the type of neurological conditions but also the number of neurological diseases a patient was suffering from, no matter whether they had an influence on gait or balance, correlated with the risk of falling. This came as a surprise as we assumed that only accumulations of neurological deficits relating to gait and balance would influence the risk for falls. Although there were no published studies on the influence of neurological diseases, it is known that persons with an impaired sense of balance have a disproportionately higher risk for falls when they acquire an additional new disease or condition, even if it is one that seems minor or not related to falling per se. Tinetti was able to demonstrate that the number of chronic diseases a patient was suffering from was highly predictive of a risk to fall, better even than a mobility score. She concluded that falling appears to result from an accumulated effect of multiple-specific disabilities. ${ }^{45}$ This would be in keeping with our other findings, that old age in combination with any neurological disease increases the risk of falling above that of healthy controls, even if it is a disease like headache. Also, in accordance with this, we found that a higher rate of depression, as reflected by a higher ADS-score, also increased the risk for falls. An alternative explanation for this could be that depressive thoughts are frequently combined with negative conceptions of one's own sense of balance, which was found to be a prominent risk factor for falls in our and previous other studies. ${ }^{46}$

That higher age would be a predictive factor for falls in neurological patients replicates previous findings ${ }^{13}$ and is easy to explain: old age is often associated with greater frailty and eventually frailty with less confidence in one's sense of balance and a higher incidence of falls. ${ }^{46}$ That women are more prone to falls than men has often been stated before ${ }^{13}$ and has previously been explained by a fear of falling and a loss of confidenceboth independent risk factors for falls-being more prominent in women. ${ }^{6}$ 


\section{LIMITATIONS}

We also faced several limitations in our study. First and most importantly, like most other surveys dealing with falls, we faced the problem that the number of falls are likely to be under-reported. Elderly participants often try to downplay problems regarding their mobility for fear of having their autonomy restricted. While this is in general typically found in the healthy elderly, it might be even more prominent in patients with disabilities. But even remembering these events might pose a problem in some of the patients with central degenerative diseases, which might have been a relevant factor in our study, even though we excluded patients with severe dementia. The risk for falls in neurological patients might therefore be greater than shown in any results. Future prospective studies could minimise this problem by using patients' diaries according to established guidelines for reporting falls, ${ }^{47}$ possibly even in combination with wearable miniaturised electronic devices apt to objectively detect and monitor falls. ${ }^{48}$

Second, the large dropout rate of $23 \%$ from neurological assessment to interview, not containing the $3.6 \%$ that had to be excluded prior to recruitment due to an inability or unwillingness to participate, could have led to further underestimating the number of patients with falls. However, since these patients did not obviously differ in their baseline characteristics, we assume this problem to be minimal.

Then, we would also like to address the issue of small sample sizes in subgroups of neurological diseases. Some of the groups like vascular diseases, movement disorders, vertebral pain and peripheral neuropathy are adequately sized, and even outnumber participants of single disease studies like those on peripheral neuropathy. ${ }^{41}{ }^{43}$ Others, particularly the dementia group with only seven patients, are, due to the exclusion of the more affected, quite small and allow only limited extrapolation. Nevertheless, it is remarkable that even here the analysis of difference reached levels of significance.

\section{CONCLUSION}

It can be said that we managed to show, apparently for the first time, that even among ambulatory neurological outpatients, falls are alarmingly frequent. The aetiology of falls is multifactorial, but the connection between falls and disturbances of the sensorimotor system frequently found in neurological diseases in elderly patients is of great importance. Our findings revealed that even neurological diseases not directly connected with gait and balance carry an astonishingly high risk for falls. Medical practitioners, allied health professionals and carers should therefore be aware that their patients are at high risk for falls, as any neurological deficit increases this risk, even more so if a combination of factors is present. Of course, the risk has to be evaluated individually, but patients with central diseases like stroke, PD, dementia and epilepsy and, for repeated falls, also patients with peripheral neurological disorders require special attention. Greater disability, higher age, female gender, depression and low confidence in the sense of balance are additional contributory factors that have to be taken into account in this process. For patients with several of these factors, targeted prevention programmes should be implemented. However, although they have been shown to generally reduce falls and injuries in the community dwelling elderly, ${ }^{49}$ there is but inconclusive evidence for patients following stroke ${ }^{50}$ and with $\mathrm{PD}^{51} 52$ and even more scanty information for patients with other neurological diseases. Therefore, further larger scale multicenter neurogeriatric surveys with larger sample sizes for neurological subgroups should be performed not only to confirm our observations but also to acquire more extensive knowledge of the effectiveness of preventive measures in patient cohorts with various neurological conditions and different degrees of disability. These studies should also include more objective monitoring systems and include further potential risk factors like medication and fear of falling.

Acknowledgements The authors acknowledge the study participants for their help and participation.

Contributors $\mathrm{BH}$ was involved in drafting/revising the manuscript, study concept or design, analysis or interpretation of data; AP and MG contributed to the analysis or interpretation of data, acquisition of data of patients and controls, study concept or design; AH contributed to the acquisition of data of patients and controls; TG contributed to the acquisition of data, study concept or design; EH contributed to the statistical analysis, analysis or interpretation of data, study concept or design; GI and FF contributed to the drafting/ revision of the manuscript, study concept or design and critical revision of the manuscript for important intellectual content; $\mathrm{CNH}$ was involved in the drafting/revision of the manuscript, study concept or design, acquisition of data and study supervision.

Funding This research received no specific grant from any funding agency in the public, commercial or not-for-profit sectors.

Competing interests None.

Patient consent Obtained.

Ethics approval This study was approved by the Ethics Committee of the Medical University Graz.

Provenance and peer review Not commissioned; externally peer reviewed.

Data sharing statement An additional section of the questionnaire dealt with specific risk situations when using public transport, fear of falling in these situations and general mobility issues. These issues are not directly related to the present investigation and are planned, once the analysis is completed, to be included in a separate publication.

Open Access This is an Open Access article distributed in accordance with the Creative Commons Attribution Non Commercial (CC BY-NC 3.0) license, which permits others to distribute, remix, adapt, build upon this work noncommercially, and license their derivative works on different terms, provided the original work is properly cited and the use is non-commercial. See: http:// creativecommons.org/licenses/by-nc/3.0/

\section{REFERENCES}

1. WHO. WHO global report on falls prevention in older age. Geneva, Switzerland: World Health Organization, 2007.

2. Gillespie LD. Preventing falls in older people: the story of a Cochrane review. Cochrane Database Syst Rev 2013;(2):ED000053. 
3. Luukinen $\mathrm{H}$, Koski $\mathrm{K}$, Hiltunen $\mathrm{L}$, et al. Incidence rate of falls in an aged population in northern Finland. $J$ Clin Epidemiol 1994;47:843-50.

4. Sattin RW, Lambert Huber DA, DeVito CA, et al. The incidence of fall injury events among the elderly in a defined population. $A m \mathrm{~J}$ Epidemiol 1990;131:1028-37.

5. Sleet DA, Moffett DB, Stevens J. CDC's research portfolio in older adult fall prevention: a review of progress, 1985-2005, and future research directions. J Safety Res 2008;39:259-67.

6. Collerton J, Kingston A, Bond J, et al. The personal and health service impact of falls in 85-year-olds: cross-sectional findings from the Newcastle 85+ cohort study. PLOS ONE 2012;7:e33078.

7. O'Loughlin JL, Robitaille Y, Boivin JF, et al. Incidence of and risk factors for falls and injurious falls among the community-dwelling elderly. Am J Epidemiol 1993;137:342-54.

8. Deandrea S, Lucenteforte E, Bravi F, et al. Risk factors for falls in community-dwelling older people: a systematic review and meta-analysis. Epidemiology 2010;21:658-68.

9. Guillochon A, Crinquette C, Gaxatte C, et al. Neurological diseases detected in the Lille Multidisciplinary Falls Consultation. Rev Neurol (Paris) 2010;166:235-41.

10. Lamb SE, Ferrucci L, Volapto S, et al. Risk factors for falling in home-dwelling older women with stroke: the Women's Health and Aging Study. Stroke 2003;34:494-501

11. Paul SS, Canning CG, Sherrington C, et al. Three simple clinical tests to accurately predict falls in people with Parkinson's disease. Mov Disord 2013;28:655-62.

12. Horikawa E, Matsui $\mathrm{T}$, Arai $\mathrm{H}$, et al. Risk of falls in Alzheimer's disease: a prospective study. Intern Med 2005;44:717-21.

13. Stolze $\mathrm{H}$, Klebe $\mathrm{S}$, Zechlin $\mathrm{C}$, et al. Falls in frequent neurological diseases-prevalence, risk factors and aetiology. J Neurol 2004;251:79-84.

14. Mahoney FI, Barthel DW. Functional evaluation: the Barthel Index. Md Med 1965;14:61-5.

15. Fahn S, Elton RL, and members of the UPDRS committee. Unified Parkinson's Disease Rating Scale. In: Fahn S, Marsden CD, Goldstein M, Calne DB, eds. Recent developments in Parkinson's Disease. New Jersey: McMillan Health Care, 1987:153-63.

16. Hautzinger M, Bailer M. Allgemeine depressions skala, manual. Göttingen: Beltz Test GmbH, 1993.

17. Radloff LS. The CES-D scale. Appl Psychol Meas 1977;1:385-401.

18. Schrag A, Barone P, Brown RG, et al. Depression rating scales in Parkinson's disease: critique and recommendations. Mov Disord 2007;22:1077-92.

19. Peretz C, Herman T, Hausdorff JM, et al. Assessing fear of falling can a short version of the Activities-specific Balance Confidence scale be useful? Mov Disord 2006;21:2101-5.

20. Forster A, Young J. Incidence and consequences of falls due to stroke: a systematic inquiry. BMJ 1995;311:83-6.

21. Lord SR, Sambrook PN, Gilbert C, et al. Postural stability, falls and fractures in the elderly: results from the Dubbo Osteoporosis Epidemiology Study. Med J Aust 1994;160:684-85, 688-91.

22. Prudham D, Evans JG. Factors associated with falls in the elderly: a community study. Age Ageing 1981;10:141-6.

23. Campbell AJ, Borrie MJ, Spears GF, et al. Circumstances and consequences of falls experienced by a community population 70 years and over during a prospective study. Age Ageing 1990;19:136-41.

24. Blake AJ, Morgan K, Bendall MJ, et al. Falls by elderly people at home: prevalence and associated factors. Age Ageing 1988;17:365-72

25. Tinetti ME, Speechley M, Ginter SF. Risk factors for falls among elderly persons living in the community. N Engl J Med 1988;319:1701-7.

26. Campbell AJ, Borrie MJ, Spears GF. Risk factors for falls in a community-based prospective study of people 70 years and older. J Gerontol 1989:44:M112-17.

27. Hirtz D, Thurman DJ, Gwinn-Hardy K, et al. How common are the "common" neurologic disorders? Neurology 2007;68:326-37.

28. Schmid AA, Kapoor JR, Dallas M, et al. Association between stroke severity and fall risk among stroke patients. Neuroepidemiology 34:158-62.
29. Bloem BR, van Vugt JP, Beckley DJ. Postural instability and falls in Parkinson's disease. Adv Neurol 2001;87:209-23.

30. Soriano TA, DeCherrie LV, Thomas DC. Falls in the community-dwelling older adult: a review for primary-care providers. Clin Interv Aging 2007;2:545-54.

31. Fletcher PC, Hirdes JP. Risk factors for falling among communitybased seniors using home care services. J Gerontol A Biol Sci Med Sci 2002;57:M504-10.

32. Yates JS, Lai SM, Duncan PW, et al. Falls in community-dwelling stroke survivors: an accumulated impairments model. J Rehabil Res Dev 2002;39:385-94

33. Balash $\mathrm{Y}$, Peretz $\mathrm{C}$, Leibovich $\mathrm{G}$, et al. Falls in outpatients with Parkinson's disease: frequency, impact and identifying factors. J Neurol 2005;252:1310-15.

34. Koller WC, Glatt S, Vetere-Overfield B, et al. Falls and Parkinson's disease. Clin Neuropharmacol 1989;12:98-105.

35. Ashburn A, Stack E, Pickering RM, et al. Predicting fallers in a community-based sample of people with Parkinson's disease. Gerontology 2001;47:277-81.

36. Gray P, Hildebrand K. Fall risk factors in Parkinson's disease. $J$ Neurosci Nurs 2000;32:222-8.

37. Wood BH, Bilclough JA, Bowron A, et al. Incidence and prediction of falls in Parkinson's disease: a prospective multidisciplinary study. J Neurol Neurosurg Psychiatry 2002;72:721-5.

38. Pickering RM, Grimbergen YA, Rigney U, et al. A meta-analysis of six prospective studies of falling in Parkinson's disease. Mov Disord 2007;22:1892-900.

39. Hely MA, Reid WG, Adena MA, et al. The Sydney multicenter study of Parkinson's disease: the inevitability of dementia at 20 years. Mov Disord 2008;23:837-44.

40. Ryan JJ, McCloy C, Rundquist $P$, et al. Fall risk assessment among older adults with mild Alzheimer disease. J Geriatr Phys Ther 2011;34:19-27.

41. DeMott TK, Richardson JK, Thies SB, et al. Falls and gait characteristics among older persons with peripheral neuropathy. $\mathrm{Am}$ $J$ Phys Med Rehabil 2007;86:125-32.

42. Richardson JK, Ching C, Hurvitz EA. The relationship between electromyographically documented peripheral neuropathy and falls. J Am Geriatr Soc 1992;40:1008-12.

43. Richardson JK, Hurvitz EA. Peripheral neuropathy: a true risk factor for falls. J Gerontol A Biol Sci Med Sci 1995;50:M211-15.

44. Flierl-Hecht A, Pfafflin M, May TW, et al. Is epilepsy in the elderly overlooked? An investigation in a home for the aged. Nervenarzt 2003;74:691-8.

45. Tinetti ME, Williams TF, Mayewski R. Fall risk index for elderly patients based on number of chronic disabilities. Am J Med 1986;80:429-34.

46. Kose N, Cuvalci S, Ekici G, et al. The risk factors of fall and thei correlation with balance, depression, cognitive impairment and mobility skills in elderly nursing home residents. Saudi Med $J$ 2005;26:978-81.

47. Lamb SE, Jorstad-Stein EC, Hauer K, et al. Development of a common outcome data set for fall injury prevention trials: the Prevention of Falls Network Europe consensus. J Am Geriatr Soc 2005;53:1618-22.

48. Howcroft J, Kofman J, Lemaire ED. Review of fall risk assessment in geriatric populations using inertial sensors. J Neuroeng Rehabil 2013:10:91.

49. Oliver D, Connelly JB, Victor CR, et al. Strategies to prevent falls and fractures in hospitals and care homes and effect of cognitive impairment: systematic review and meta-analyses. BMJ 2007;334:82.

50. Verheyden GS, Weerdesteyn V, Pickering RM, et al. Interventions for preventing falls in people after stroke. Cochrane Database Syst Rev 2013;(5):CD008728.

51. Goodwin VA, Richards SH, Henley W, et al. An exercise intervention to prevent falls in people with Parkinson's disease: a pragmatic randomised controlled trial. J Neurol Neurosurg Psychiatry 2011;82:1232-8.

52. Li F, Harmer $\mathrm{P}$, Fitzgerald $\mathrm{K}$, et al. Tai chi and postural stability in patients with Parkinson's disease. N Engl J Med 2012;366:511-19. 